\title{
AN INVESTIGATION INTO CURRENT ATTITUDES TOWARDS ENGLISH AT THE UNIVERSITY OF THE WESTERN CAPE
}

\section{Charlyn Dyers}

This work-in-progess paper describes the writer's current research into the language attitudes, preferences and usage of the student speech community at the University of the Western Cape. It specifically looks at responses to questions on English which formed part of a larger survey questionnaire on South African languages, and attempts an analysis of these results.

Hierdie artikel beskyf die huidige navorsing van die skyfster oor die houdings teenoor tale, die verkieslikheid van een taal bo 'n ander en die taalgebruik van studente by die Universiteit van Wes-Kaapland. Dit fokus in die besonder op antwoorde tot vrae oor Engels wat deel was van 'n groter verkennende vraelys oor Suid Afrikaanse tale, en poog om hierdie resultate te analiseer.

\section{INTRODUCTION}

Language attitudes can be defined as the strong positive or negative emotions experienced by people when they are faced with a choice between languages in a variety of situations or are learning a language. While language attitudes are often deep-seated and private (and therefore very difficult to assess), language preferences are openly expressed, such as a preference for conducting business affairs in a particular language. The relevance of research in this area cannot be overstated within the context of the new South Africa. After a century of only two official languages (English and Afrikaans), South Africans now have a choice of eleven official languages (English, Afrikaans, Xhosa, Zulu, Venda, Tsonga, Pedi, Sotho, Tswana, Ndebele and Tswati), and it is very important for language policy-makers and planners to take note of people's language attitudes and preferences so that their policies can reflect "the needs of the people, and not the interests of any particular language" (Webb, 1996:186).

My current field of research is a longitudinal examination of the language attitudes, preferences and usage among students at the University of the Western Cape. Most recent studies on language attitudes in South Africa have tended to focus largely on attitudes to English (Mawasha, 1986; Chick, 1992; Heugh, 1993; Bosch and de Klerk, 1996), and to a lesser extent on attitudes to Afrikaans (Young, 1992; Dyers, 1997) and African mother tongues (Msimang, 1994; Mashamaite, 1992). All the above-mentioned studies have made use of either African or Coloured respondents, and all the studies on attitudes to English have indicated a strong positive attitude towards English as "a pragmatic necessity" (Bosch and de Klerk, 1996:235), even though "the admiration for educated English is tempered by a strong desire to show ethnic identity when speaking English" (ibid:235). 
My research is an attempt not only to find out how the students feel about their own and all other South African languages, but also to see whether, over a period of time, language attitudes and preferences remain relatively fixed or become more flexible as a result of the influence of a variety of factors such as identifying with one's in-group or becoming exposed to a wider range of opinions on language. Baker (1988:78) believes that "in attitude change lies one hope for language life and resurrection". This observation is particularly pertinent when one considers the "privileged and dominant status" of English in South Africa which could lead to the "neglect, marginalisation and even ultimate extinction of some or all of the other indigenous languages through their lack of functional demand" (Young, 1995:65). Changing people's attitudes towards both English and all other South African languages may be a means of reversing such a trend.

Over a period of three years, the same UWC students will have been surveyed by me to see whether they show any change in their language attitudes and preferences as they progress through university, and how such change influences their language use. My central hypothesis is that their language experiences and particularly the specific nature of UWC as a unique speech community in the context of the largely Afrikaans-speaking Western Cape, will lead to either slight or significant changes in their attitudes to, and preferences for, languages, and these changes will in turn affect their language use.

While people may hold specific attitudes to languages which may either positively or negatively influence how well they learn those languages (Roos, 1990:27), or express distinct preferences for the languages they wish to use in different situations (Eastman, 1992:111), their actual language use may very well contradict their language attitudes and preferences. Gough (1994:40) shows this contradiction by pointing out that (among white South Africans) "conservative Afrikaans farmers... reveal the greatest knowledge of African (Bantu) languages... which probably could not be said to be true for white supporters of more progressive parties (who may, in fact, see this as politically desirable)". Speakers of African languages, in contrast, may reveal strong negative attitudes towards Afrikaans because of its past political connotations (Dyers, 1997:26), but may actually be highly competent users of the language. It is likely that my research will give further evidence of this contradiction between attitude/preference and use.

The first aspect of this research is the question of which languages are most commonly used by the students at UWC. Within this community, where English operates as the main lingua franca, there are several distinct speech communities. There is the majority Xhosa-speaking group, who currently constitute $44.2 \%$ of the total student population, the fairly large Afrikaans/Bilingual in English and Afrikaans (23.2\%) and English-speaking (18.7\%) groups, and the smaller Zulu-speaking (2.9\%) group. There are also small pockets of speakers of other languages at UWC. The above figures, obtained from UWC Student Records, apply to the 1997 student population.

Particular attention is being given to particular factors which can influence these students' responses to the different South African languages, to see whether "the choice and use of English or a local language in a particular situation is associated with value connotations of status or in-group identity" (Siachitema, 1985:202). Among these factors are:

English is "the de facto ... main language of teaching and learning at UWC" (Cornell 1996:2) (few lecturers use Afrikaans); 
$37.2 \%$ of all students come from other provinces (UWC Student Records, 1997) and the majority of these now find themselves in a province where (with the exception of the English, Afrikaans and Xhosa-speaking groups) their languages are considered to be minority languages;

many students have to deal with overt and covert racism (as reported by several students in tutorial discussions and individual interviews) as well as linguicism (Hibbert, 1995:128). They must also become part of new social groupings on and off campus.

All these factors may exert a strong influence on language attitudes and language use.

This article is confined to an exploration of first-year students' responses to questions related to English within a larger survey that dealt with attitudes to all 11 official South African languages, as well as an exploration of some of the reasons given for these attitudes during follow-up interviews.

\section{THE STUDY: DATA COLLECTION AND ANALYSIS}

This study on first-year student responses to English forms part of a larger study which explores the attitudes students have towards their mother tongues, Afrikaans and other South African languages. The respondents in the study are all students who did the English 105 course in their first year (1996).

English 105 is UWC's academic literacy course, which aims to provide first-year students with the language and study skills they need to cope in an academic environment. I decided to use English 105 students because they are drawn from virtually every faculty on campus, and in this sense can be said to be representative of the wider student population. I am also a lecturer on this course, and therefore have easy access to this large pool of respondents.

In September of 1996, three English 105 lecture groups took part in the survey, and 25 randomly-selected students from my own lecture group were interviewed as a follow-up to the questionnaire. 344 Multiple-choice answer sheets were collected, of which 252 were valid for the purposes of this study. Validity was determined on the basis of respondents having filled in the answer sheet correctly, and on whether they were actual first-year students in 1996. Answer sheets were invalid if students had darkened more than one of the five circles (numbered a-e) on the answer sheet in response to each survey item, or had scratched out one answer and filled in another, as the computer would only accept the first darkened circle as the answer.

The survey questionnaire, entitled Language Attitudes, Preferences and Usage, consisted of five sections:

I. Personal Information - this section reveals the respondent's age, sex, matric results overall and in languages, and year of study at university. 
II. Language Profile - this section reveals who speaks what languages to whom and under which circumstances, as well as their self-reported competencies in all South African languages.

III. Language Education Profile - this section reveals what languages were learned formally at school and university, and what languages have been acquired informally.

IV. Language Attitude Profile - this section reveals their general attitudes towards English, African languages and Afrikaans.

V. Language in Education Attitude Profile - this section reveals their attitudes towards English, African languages and Afrikaans within the educational sphere.

The first three sections were aimed at building up an overall picture of the respondent and his/her language usage as well as language preference. The last two sections, consisting of 33 statements, focussed mainly on attitude, and to a lesser extent on preference. The respondents were asked to indicate whether they
a. agreed strongly
b. agreed
c. were unsure about
d. disagreed or
e disagreed strongly with each statement.

Students answered the questionnaire by darkening the appropriate symbol (a-e) on a standard UWC multiple-choice computer answer sheet, which was then fed directly into the computer in order to obtain the results. Great care was taken during the survey sessions to ensure that students fully understood the meaning of each statement in order to ensure the accuracy of their responses. The follow-up interviews then asked students to give reasons for their responses to the attitude statements in sections IV and V.

\section{THE STUDY: FINDINGS AND DISCUSSION}

The findings are presented and discussed in the following order. Firstly, the responses to statements related to English language usage in Sections I and II of the survey will be presented. This will reveal the self-reported English language profile of the 252 students surveyed. Secondly, in order to determine the relationship between their English language profile and their attitudes towards the use of English in education, their responses to questions on English in Section V, "Language in Education Attitudes", will be presented. The results of these three sections, as they pertain to English, will then be discussed together. Finally, the results of section IV, which focusses on general attitudes towards English, will be presented and discussed. To simplify the presentation of the results, I have added responses which agree/strongly agree together, and done the same with responses which disagree/disagree strongly. This will reduce the categories of responses to three: agree, undecided and disagree. Comments taken from individual interviews will also form part of this section. 


\subsection{Language Profile}

Of the 252 respondents, only 6 were English home language users, and a mere 22 used English to communicate with friends outside UWC. The vast majority of the respondents $(79.8 \%)$ were Xhosa home language users, with smaller pockets of other language users. Of the total number of respondents, $81 \%$ had obtained either a D, E or F symbol in English in matric (D:43.1\%; E and below E:37.5\%). Despite these poor matric results, a large number of respondents (64.6\%) felt that their English was "good to excellent" while only $35.4 \%$ classified themselves as "average to poor". $88.9 \%$ had learned English as their second language at school, and all of them were of course doing English 105 at university.

\subsection{Language in Education Attitudes}

This sub-section shows how students responded to the 6 statements dealing directly with English in education.

"47. The mother-tongue should be used together with English as the medium of instruction at primary and secondary school."

$84 \%$ agreed; $8 \%$ were undecided; $8 \%$ disagreed.

"49. I enjoyed the way English was taught at school."

$76 \%$ agreed; $8 \%$ were undecided; $16 \%$ disagreed.

"51. English should be the only medium of instruction at UWC."

$70 \%$ agreed; $7 \%$ were undecided; $23 \%$ disagreed.

"59. I feel that I have enough English to enable me to cope with university studies."

$57 \%$ agreed; $20 \%$ were undecided; $23 \%$ disagreed.

"60. I find it difficult studying my subjects in a language that is not my mother-tongue - in this case, English."

$37 \%$ agreed; $11 \%$ were undecided; $52 \%$ disagreed.

"64. The use of the mother tongue in English 105 tutorials improved my understanding of English as well as my confidence in using it."

$40 \%$ agreed; $13 \%$ were undecided; $47 \%$ disagreed.

\subsection{Discussion of the results of the language profile and language in education attitudes}

The majority of the students appear to have enjoyed learning English at school, and would like to see it used together with mother-tongues from primary school onwards. It is also their preferred medium of instruction at UWC. Comments made with regards to this issue during follow-up interviews included:

"Most academic textbooks are written in English."

"If you want to study in other countries you need English." 
"It would prove too costly and be divisive for everyone to be instructed in his/her mother tongue."

These findings confirm earlier studies (Mawasha, 1996:23; Chick, 1992:31) which show that black people in South Africa prefer English as a medium of instruction, even from the earliest years of primary schooling. The majority of these students feel comfortable with their level of English, and more than half of the respondents feel that they have enough English to cope with their university studies. The interviews showed that many of these students felt that the nine months they had spent in English 105 had played a significant role in increasing their competence in English for academic purposes.

This confidence is, however, not supported by their poor matric results in English, nor by the fact that one of the reasons so many students fail their university studies annually is because their level of English is insufficient (Sinclair, 1992:82; Agar, 1990:435-454). In another survey done at UWC in 1992 on first-years from the faculties of Law, Science and Community and Health Sciences, Volbrecht (1992:30) also concluded that "most students have an unrealistically high estimation of their proficiency in English for academic purposes".

It is interesting to note the results of questions related to tutorials, where one might assume that students would be willing to use their mother-tongues. But this is not clearly the case. The responses to statement 64 show that students appear to be undecided about whether the mothertongue is a help or a hindrance in learning English. In two other statements related to tutorials, $80 \%$ of respondents felt that it caused problems in tutorials when everyone was allowed to speak in their mother-tongues, while only $39 \%$ preferred to use their mother-tongues during discussions in tutorials. Actual class room observations by the writer contradicts these negative responses to the use of the mother tongue in tutorials. Most students in English 105 tutorials do in fact chat in their mother tongues to fellow mother-tongue speakers, but are, according to this survey, reluctant to acknowledge this fact. However, if paired or grouped with speakers of other languages for classroom exercises, English, together with some code-switching where needed, seems to be the only practical choice to permit mutual understanding.

The follow-up interviews have also revealed that some students are anxious about creating any racial tensions in these tutorials, which might be provoked by small groups insisting on using their mother-tongues, to the exclusion of others. For example, non-Xhosa speaking African students complain about Xhosa students' insistence on addressing them in Xhosa, Afrikaans students are angered by "people who deliberately refuse to speak Afrikaans" and most African students are anxious not to exclude Coloured students from discussions (see Dyers, 1996:28-9 and Hibbert, 1995:129-130).

\subsection{General Language Attitudes}

This is how students responded to the four statements dealing directly with English in this section.

"33. There should be one common language, and it should be English."

$66 \%$ agreed with this statement; $5 \%$ were undecided; $29 \%$ disagreed.

"40. There are too many English programmes on SABC 1 and 2." 
$69 \%$ agreed; $11 \%$ were undecided; $20 \%$ disagreed.

"42. You can't get a good job unless your English is good."

$61 \%$ agreed; $9 \%$ were undecided; $30 \%$ disagreed.

"45. English has been forced on me because of historical reasons and its power as the international language."

$57 \%$ agreed; $11 \%$ were undecided; $32 \%$ disagreed.

\subsection{Discussion of the results on general language attitudes}

Students showed a distinct preference for English as South Africa's lingua franca (statement 33). They also acknowledged it as the language of power and social mobility (statement 42), although the majority agreed that they had no choice but to opt for English because of its power as the international language (statement 45). However, they were not happy with the predominance of English on television (statement 40), preferring to hear their own languages, or multilingual TV dramas like "Generations" and "Soul City", when they were relaxing at home. The response to this statement confirms the findings of Slabbert and Van den Berg's 1994 survey on people's language choices for TV viewing, which found that English is not widely accepted as the most understood language on TV and radio and is less widely spoken than was commonly assumed.

\subsection{Analysis of the Results}

Taking all responses into account, we can say that this particular survey revealed two specific trends. Firstly, the results show that the language use of these students is domain-specific, with home languages preferred for informal interpersonal communication and relaxation, while English is the preferred medium for formal situations like education, politics and business. During one interview, a student had the following to say, which seemed to sum up the sentiments of the majority of the students surveyed and interviewed:

I don't want to use my language Xhosa because I want to have friends, to learn more about outside world, to have a better job at the end of the day. The only thing that I can do with my language is to share my feelings with my family just to know where I'm coming from, my culture and customs will remain now and forever. But in our future we must speak English so that you can communicate with different people in the world. If you speak English you have got everything that you are looking for. To me English is a better life.

Secondly, the results also demonstrate the contradiction, referred to in the introduction to this article, between a largely positive attitude towards English and the actual language usage of the students surveyed here. The poor matric results these students obtained in English do not therefore stem from a negative attitude towards English, but can be blamed on a number of other factors, of which the breakdown in education in many Black schools is one. Another important reason is highlighted by the research of Skutnabb-Kangas (1984), Cummins (1979) and Akkinaso (1993), which show the direct relationship between first language acquisition and second language learning. Past educational policies in South Africa have severely impaired sound first language development in Black children, by forcing primary school children to start 
studying nearly all their subjects through the medium of English from the fifth year at school. For this reason, many of these children are unable to transfer literacy skills in their first language to literacy skills in the second language, because these skills have not been given the opportunity to develop fully.

\section{CONCLUSIONS}

Obviously, there are shortcomings in this research - it is not possible to draw firm conclusions from one survey only, and it would be necessary to see how these students respond in their second and third year at university before we can confidently show firm trends in their attitudes towards English. A very interesting aspect of the research has been that students with a good command of English can often be found among the minority who argue most fervently for the increased use of their mother tongues (in particular, Afrikaans and Xhosa) in lectures and tutorials at UWC. If students continue to develop their ability in English as they progress through university, they might possibly be able to articulate their position with regards to English with more conviction, and may even shift to a less overwhelmingly pro-English stance. Another factor that might influence the results, particularly in the interviews, is the fact that they are being interviewed by their English lecturer. This unequal power relationship can affect the honesty of their responses. Using peer tutors or fellow students to conduct the interviews (especially in the mother tongues of the respondents) may produce quite different results.

The main conclusion that can be drawn from this study is that the majority of the first-year students I have surveyed reflect the most common attitudes towards English in the black South African communities. Although their command of English is often inadequate, English is the preferred medium of instruction and lingua franca of the majority of the students surveyed. If English is "the language most favoured by the masses" (Kamwangamalu, 1995) then the challenge to educators, policy-makers and government is not to waste this positive attitude, but to accommodate it in an upgraded and vastly improved system of English language teaching in our schools. However, this should not occur at the expense of first giving children a firm grounding in their home languages to ensure the development of their primary literacy.

\section{REFERENCES}

AGAR, D. 1990. Non-traditional students: perceptions of problems which influence academic success. SA Journal of Higher Education, Special Edition, p. 435-454.

BAKER, C. 1988. Key issues in bilingualism and bilingual education. Clevedon: Multilingual Matters.

BOSCH, B. AND V DE KLERK. 1996. Language attitudes and their implications for the teaching of English in the Eastern Cape. In De Klerk, V. (ed.). 1996: pp. 231250 .

BOUGHEY, J. (ed) 1992. Applied language studies in Southern Africa - visions and realities. Selected proceedings from the 11 th annual SAALA conference, University of Cape Town. 
CHICK, K. 1992. English as a medium and as a subject in a post-apartheid South Africa. Southern African Journal of Applied Language Studies 1(1): 29-40.

CORNELL, C. 1996. Editorial, AD Issues (UWC) Cornell, C. and Goodman, K. (eds.) 4(1): 2

CUMMINS, J. 1979. Linguistic interdependence and the educational development of bilingual children. Review of Educational Research 49.

DE KLERK, V. (ed.) 1996. Varieties of English around the world. General Series 15: Focus on South Africa. Amsterdam: John Benjamin Publishing Co.

DYERS, C. 1996. Language attitudes among first year students at the University of the Western Cape. AD Issues 4(1): 27-29.

DYERS, C. 1997. Uncovering attitudes towards Afrikaans at UWC. Karring, 24-27.

GARDNER, R. 1982. Language attitudes and language learning. In Ryan, EB and H Giles (eds.) Attitudes towards language variation, social and applied contexts. London: Edward Arnold: 132-147.

GOUGH, D. 1994. Myths of multilingualism: demography and democracy. BUA! 9(3): 9-11.

HEUGH, K, A SIEGRUHN, P PLUDDEMANN. 1995. Multilingual education for South Africa Johannesburg: Heinemann.

HEUGH, K. 1995. Disabling and enabling: implications of language policy trends in South Africa. In Meshrie, R. (ed.): 329-350.

HIBBERT, L 1995. Xhosa in the English Tutorial - Bridge or Barrier? in AD Dialogues 4: 119134.

KAMWANGAMALU, N. 1995. English in language planning in the new South Africa. In Constitutionally Enshrined Multilingualism: Challenges and Responses. Proceedings of the 15th Annual Conference of the South African Applied Linguistics Association. University of Stellenbosch: 85-107.

MASHAMAITE, K. 1992. Standard and non-standard: towards finding a suitable teaching strategy. In South African Journal of African languages, supplement 1(12): 4755.

MAWASHA, A. 1996. Sample views of African post-graduate students regarding English and the African Languages as media of education in African Schools in South Africa. Per Linguam 12(1): 15-23.

MESHRIE, R. (ed.) 1995. Language and social history: Studies in South African Sociolinguistics. Cape Town, David Phillip. 
MSIMANG, C. 1994. Language attitudes and the harmonisation of Nguni and Sotho. In South African Journal of Linguistics. Supplement 20: Language, text and the Southern African context: 147-167.

ROOS, R. 1990. Language Attitudes in the Second Language situation. Per Linguam 6(2): 2530.

SIACHITEMA, A. 1985. Attitudes towards the use of English in three neighbourhoods of Lusaka in Language in Education in Africa. In Davies, A. (ed.). Centre for African Studies, University of Edinburgh: 201-229.

SINCLAIR, A. 1992. Reading and not understanding: the encoding problems in English of non English-speaking first year students. In Boughey (ed): 82-96.

SLABBERT, S. AND I VAN DEN BERG. 1994. Quantitative language study. Management Report. Prepared for Broadcasting Research Unit, SABC.

SKUTTNAB-KANGAS, T. 1984. Bilingualism or not: the education of minorities. Clevedon: Multilingual Matters.

VOLBRECHT, T. 1992. Report on language orientation attitude survey 1992. Unpublished Report, Academic Development Centre, UWC.

YOUNG, D. 1995. The role and status of the first language in education in a multilingual society. In Heugh et al (eds.): 53-62.

WEBB, V. 1996. English and language planning for South Africa: the flip side. In De Klerk, V. (ed.): 175-190. 